\title{
IL-4 Modulates CCL11 and CCL20 Productions from IL-1 $\beta$-Stimulated Human Periodontal Ligament Cells
}

\author{
Yoshitaka Hosokawa ${ }^{a}$ Ikuko Hosokawa ${ }^{a}$ Satoru Shindo ${ }^{a}$ Kazumi Ozaki ${ }^{b}$ \\ Takashi Matsuo \\ aDepartment of Conservative Dentistry, Institute of Biomedical Sciences, Tokushima University \\ Graduate School, Tokushima, Tokushima, b Department of Oral Health Care Promotion, Institute of \\ Biomedical Sciences, Tokushima University Graduate School, Tokushima, Tokushima, Japan
}

\section{Key Words}

IL-4 • CCL11 • CCL20 • STAT6 • Periodontal ligament cells

\begin{abstract}
Background/Aims: IL-4 is a multifunctional cytokine that is related with the pathological conditions of periodontal disease. However, it is uncertain whether IL-4 could control T cells migration in periodontal lesions. The aim of this study was to examine the effects of IL-4 on CCL11, which is a Th2-type chemokine, and CCL20, which is related with Th17 cells migration, productions from human periodontal ligament cells (HPDLCs). Methods: CCL20 and CCL11 productions from HPDLCs were monitored by ELISA. Western blot analysis was performed to detect phosphorylations of signal transduction molecules in HPDLCs. Results: IL-1 $\beta$ could induce both CCL11 and CCL20 productions in HPDLCs. IL-4 enhanced CCL11 productions from IL-1 $\beta$-stimulated HPDLCs, though IL-4 inhibited CCL20 production. Western blot analysis showed that protein kinase B (Akt) and signal transducer and activator of transcription (STAT)6 pathways were highly activated in IL-4/IL-1 $\beta$-stimulated HPDLCs. Akt and STAT6 inhibitors decreased CCL11 production, but enhanced CCL20 production in HPDLCs stimulated with IL-4 and IL-1 $\beta$. Conclusions: These results mean that IL-4 enhanced Th2 cells migration in periodontal lesion to induce CCL11 production from HPDLCs. On the other hand, IL-4 inhibits Th17 cells accumulation in periodontally diseased tissues to inhibit CCL20 production. Therefore, IL-4 is positively related with the pathogenesis of periodontal disease to control chemokine productions in periodontal lesions.

\section{Introduction}

Periodontal disease is a chronic bacterial infection of tooth-supporting tissues. It causes destruction of periodontal connective tissues and alveolar bone. The aggravation of 
periodontal disease results from the host response to bacteria in periodontal lesions [1]. Cytokines in periodontal lesions are related to the pathogenesis of periodontal disease [2]. IL-4, which is a Th2 type cytokine, is an important factor that could modulate immune response in periodontal lesion $[3,4]$. We previously reported that IL-4 could enhance VCAM1 [4], CCL17 [5] and CCL11 [6] production in human gingival fibroblasts. It is known that VCAM-1 [7], CCL17 [8] and CCL11 [9] are related to Th2 cells retention and migration in inflammatory lesion. Therefore, IL-4 could increase the number of Th2 cells in periodontal lesion. However, how IL-4 could enhance CCL11 productions from human HPDLCs is unknown.

It has been reported that Th17cells are involved in the pathological process of periodontal disease [10], and CCL20 is essential for the accumulation of Th17 cells in inflammatory lesions [11]. We previously reported that IL-1 $\beta$ could induce CCL20 production from periodontal cells, such as human gingival fibroblasts [12] and HPDLCs [13]. However, the effect of IL-4 on CCL20 production from HPDLCs is uncertain.

The aim of this study was to examine the effect of IL-4 on CCL11 and CCL20 productions from IL-1 $\beta$-stimulated HPDLCs which is a major cell in periodontal tissues. Moreover, we examined which signal transduction pathways are related to CCL11 and CCL20 productions including activation of mitogen-activated protein kinases (MAPKs), signal transducer and activator of transcription (STAT)6, and protein kinase B (Akt) pathways in IL-4 and/or IL$1 \beta$-stimulated HPDLCs.

\section{Materials and Methods}

\section{Cell culture}

HPDLCs were obtained from Lonza Walkersville Inc. (Walkersville, MD, USA) and grown in the Dulbecco's modified Eagle medium (DMEM: Gibco, Grand Island, NY, USA) supplemented with 10\% fetal bovine serum (FBS: Gibco) and antibiotics (penicillin G: 100 units $/ \mathrm{ml}$, streptomycin: $100 \mu \mathrm{g} / \mathrm{ml}$ ) at $37^{\circ} \mathrm{C}$ in humidified air with $5 \% \mathrm{CO}_{2}$. Cells were used between passage numbers 5 and 10.

\section{CCL11 and CCL20 production in HPDLCS}

The HPDLCs were stimulated with recombinant human IL-1 $\beta$ (Peprotech, Rocky Hill, NJ, USA) and/or recombinant human IL-4 (Peprotech) for 24 hours. The supernatants from the HPDLCs were collected, and the CCL11 and CCL20 concentrations of the culture supernatants were measured in triplicate with ELISA. Duoset (R\&D systems, Minneapolis, MN, USA) was used for the determination. All assays were performed according to the manufacturer's instructions, and cytokine levels were determined using the standard curve prepared for each assay. In selected experiments, the HPDLCs were cultured for 1 hour in the presence or absence of 10 DEBC hydrochloride (1 $\mu$ M: Santa Cruz Biotechnology, Santa Cruz, CA, USA) or AS 1517499 (100 nM: Axon Medchem, Groningen, The Netherlands) prior to their incubation with IL-1 $\beta$ and/or IL-4.

\section{Western blot analysis}

To confirm the IL-4 with or without IL-1 $\beta$, -induced phosphorylation of signal transduction molecules, western blot analysis was performed. HPDLCs stimulated by IL-4 (10 ng/ml) with or without IL-1 $\beta$ ( $1 \mathrm{ng} /$ $\mathrm{ml}$ ) for 15, 30, or 60 min were washed once with cold PBS, before being incubated on ice for 15 min with cell lysis buffer (Cell signaling technology, Danvers, MA, USA) supplemented with protease inhibitors cocktail (Sigma, St. Louis, MO, USA). After removal of debris by centrifugation, the protein concentrations of the lysates were quantified with the Bradford protein assay using IgG as a standard. A $20 \mu$ g protein sample was loaded onto a 4 - 20\% SDS-PAGE gel, before being electrotransfered to a PVDF membrane. The phosphorylations of p38 MAPK, ERK, JNK, Akt or STAT6 in HPDLCs were assessed using phospho-p38 MAPK rabbit monoclonal antibody (Cell signaling technology), phospho-ERK rabbit monoclonal antibody (Cell signaling technology), phospho-JNK rabbit monoclonal antibody (Cell signaling Technology), phosphoAkt rabbit monoclonal antibody (Cell signaling Technology), phospho-STAT6 rabbit monoclonal antibody (Cell signaling Technology), p38 MAPK rabbit monoclonal antibody (Cell signaling technology), ERK rabbit monoclonal antibody (Cell signaling Technology), JNK rabbit monoclonal antibody (Cell Signaling 
Technology), Akt mouse monoclonal antibody (Cell Signaling Technology), or STAT6 rabbit monoclonal antibody (Cell signaling technology), or GAPDH rabbit monoclonal antibody (Cell signaling technology) according to the manufacturer's instructions. Protein bands were visualized by incubation with the HRPconjugated secondary antibody (Sigma), followed by detection using the ECL system (GE Healthcare, Uppsala, Sweden).

Statistical analysis

Statistical significance was analyzed using the Student's $t$ test for the data shown in Fig. 1, Fig. 2, and Fig. 4. $P$ values $<0.05$ were considered significant.

\section{Results}

The effect of IL-1 $\beta$ and/or IL-4 on CCL11 production from HPDLCS

We first investigated the ability of CCL11 production from HPDLCs because there are no reports about CCL11 production from HPDLCs. IL- 4 or IL-1 $\beta$ could moderately induce CCL11 production from HPDLCs. We found that IL-4 synergistically enhanced CCL11 production from IL-1 $\beta$-stimulated HPDLCs (Fig. 1).

The effect of IL-1 $\beta$ and/or IL-4 on CCL20 production from HPDLCS

We next investigated whether IL-4 could modify CCL20 production from IL-1 $\beta$ stimulated HPDLCs. Fig. 2 shows that IL-4 inhibited CCL20 production from IL-1 $\beta$-stimulated HPDLCs in a dose-dependent manner.

The effect of IL-4 and/or IL-1 $1 \beta$ on MAPKs, $N F-\kappa B$, Akt or STAT6 activations in HPDLCs

Next, we examined whether IL-4 and/or IL-1 $\beta$ stimulation could control the activation of signal transduction pathways in HPDLCs. PI3K-Akt-mTOR pathway and MAPKs pathway are important to explain the biology of HPDLCs [13-15]. Moreover, we or other groups previously

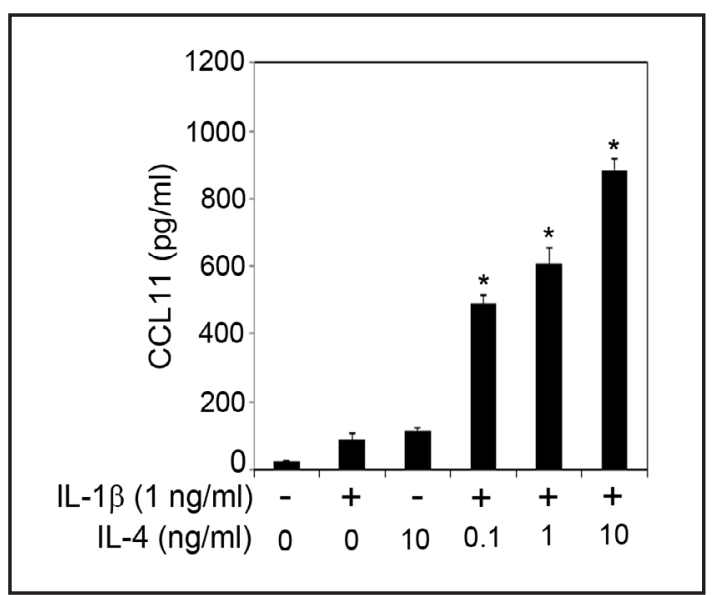

Fig. 1. The effect of IL-4 on CCL11 production in IL-1 $\beta$-stimulated HPDLCs. HPDLCs were stimulated with IL-4 $(0.1,1$, or $10 \mathrm{ng} / \mathrm{ml})$ and/or IL-1 $\beta$ (1 ng/ $\mathrm{ml}$ ), and the supernatants were collected after 24 hours. The expression levels of CCL11 in the supernatants were measured using ELISA. The results are shown as the mean and SD of one representative experiment performed in triplicate. The error bars show the SD of the values. ${ }^{*}=P<0.01$ significantly different from the IL-1 $\beta$-stimulated HPDLCs.

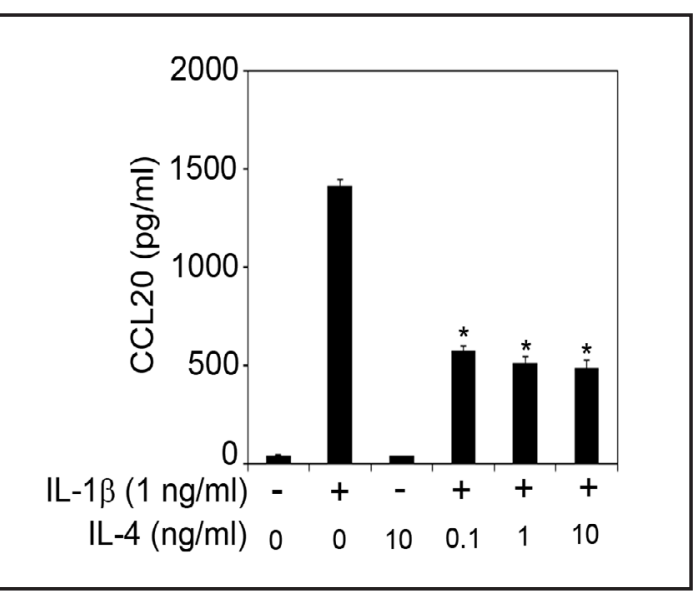

Fig. 2. The effect of IL-4 on CCL20 production in IL-1 $\beta$-stimulated HPDLCs. HPDLCs were stimulated with IL-4 $(0.1,1$, or $10 \mathrm{ng} / \mathrm{ml})$ and/or IL-1 $\beta$ (1 $\mathrm{ng} / \mathrm{ml}$ ), and the supernatants were collected after 24 hours. The expression levels of CCL20 in the supernatants were measured using ELISA. The results are shown as the mean and SD of one representative experiment performed in triplicate. The error bars show the SD of the values. ${ }^{*}=P<0.01$ significantly different from the IL-1 $\beta$-stimulated HPDLCs. 
Fig. 3. Phosphorylations of p38 MAPK, ERK, JNK, NF- $\kappa$ B p65, Akt, and STAT6 in IL-4 and/or IL-1 $\beta$-stimulated HPDLCs. The cultured cells were stimulated with IL-4 (10 ng/ml each) and/or IL-1 $\beta$ ( $1 \mathrm{ng} / \mathrm{ml})$ for 15 , 30 , or $60 \mathrm{~min}$. The cell extracts were subjected to SDS-PAGE followed by. Western blotting analysis with antibodies against phospho-specific p38 MAPK, p38 MAPK, phospho-specific ERK, ERK, phosphor-specific JNK, JNK, phospho-specific NF-кB p65, NF- $\kappa$ B p65, phospho-specific Akt, Akt ,phospho-specific STAT6, STAT6, or GAPDH. Data represent one experiment of three different experiments.

Fig. 4. Effects of an Akt inhibitor or a STAT6 inhibitor on CCL11 and CCL20 production from IL-4 and IL-1 $\beta$-stimulated HPDLCs. The cells were pre-incubated with 10-DEBC hydrochloride $(1 \mu \mathrm{M})$ or AS1517499 (100 nM) for 1 hour and then incubated with IL-4 (10 ng/ml) and IL-1 $\beta$ (1 ng/ml). After 24 hours incubation, the supernatants were collected, and CCL11 (A) and CCL20 (B) productions were measured by ELISA. The results are shown as the mean and SD of one representative experiment performed in triplicate. The error bars show the SD of the values. ${ }^{*}=P<0.05$ significantly different from the IL-4 and IL-1 $\beta$-stimulated HPDLCs without the inhibitor.
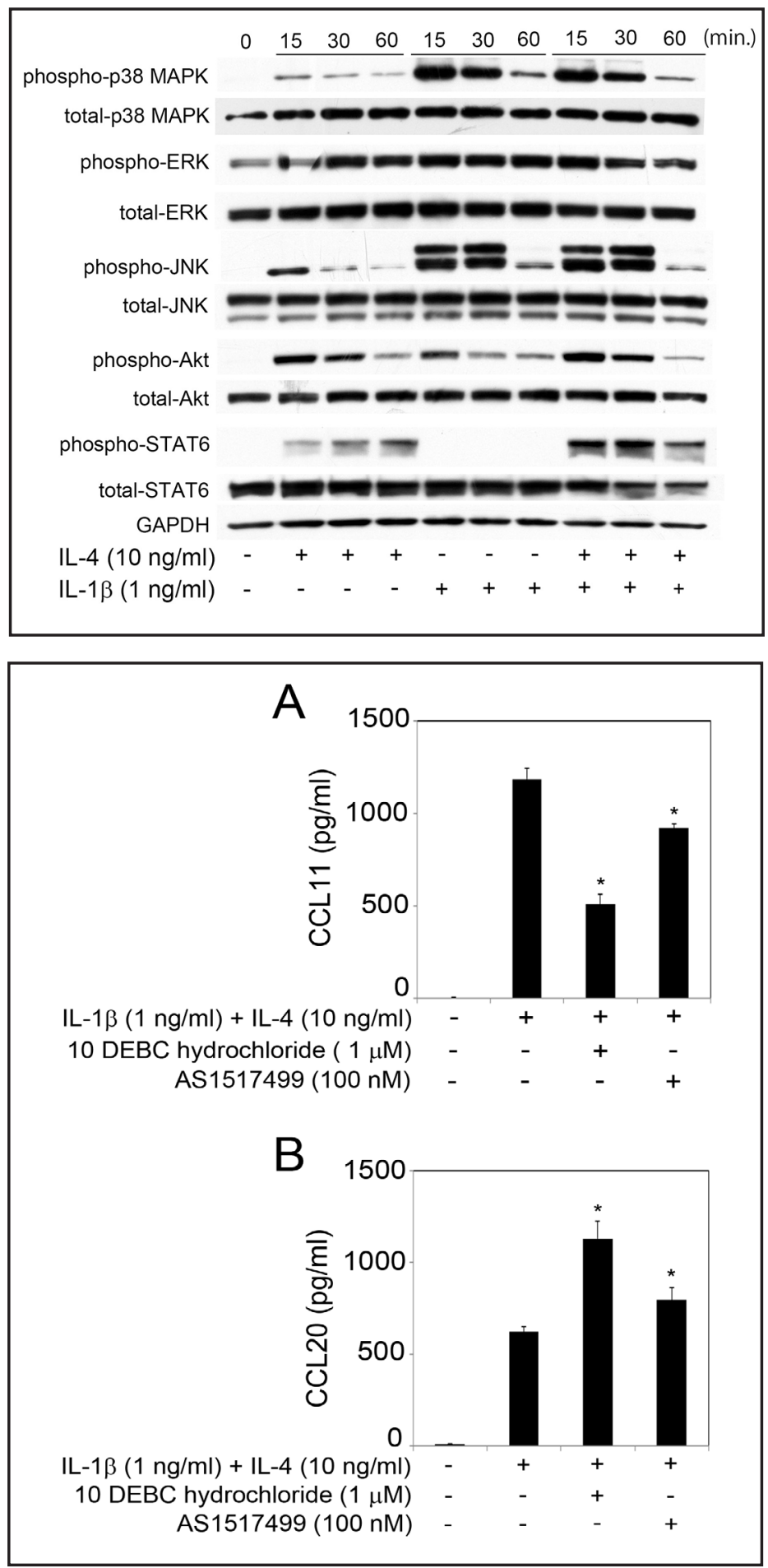

reported that IL-1 $\beta$ stimulation induced MAPKs and Akt activations in HPDLCs $[16,17]$. Moreover, it is known that IL-4 strongly activated STAT6 pathway in some types of cells [1820] though there are no reports about STAT6 activation in HPDLCs. Therefore, we examined the activations of MAPKs, Akt, and STAT6 pathways. Fig. 3 shows that IL-4 stimulation did not change MAPKs phosphorylations compared with IL-1 $\beta$-stimulated HPDLCs. The level of Akt phosphorylation is enhanced in IL- 4 and IL-1 $\beta$-stimulated HPDLCs compared to in IL-1 $\beta$-stimulated HPDLCs. Moreover, STAT6 phosphorylation is more activated in IL-4 and IL-1 $\beta$-stimulated HPDLCs than IL-4-stimulated HPDLCs.

\section{KARGER}




\section{Cellular Physiology Cell Physiol Biochem 2016;38:153-159 \begin{tabular}{cc|ccc} 
DOI: 10.1159/000438617 & O 2016 The Author(s). Published by S. Karger AG, Basel \\
www.kargercom/cpb
\end{tabular} \\ Hosokawa et al.: IL-4 Modulates Chemokine Productions in Fibroblast}

The effects of Akt and STAT6 inhibitors on CCL11 or CCL20 productions in HPDLCS stimulated with $I L-4$ and $I L-1 \beta$

Western blot analysis revealed that IL- 4 and IL-1 $\beta$ stimulation enhanced the activations of STAT6 and Akt pathways in HPDLCs compared to IL-1 $\beta$-stimulated HPDLCs. Therefore, we hypothesized Akt and/or STAT6 pathways might control CCL11 and CCL20 productions from IL-4/IL-1 $\beta$-stimulated HPDLCs. Figure 4A shows that both Akt and STAT6 inhibitors decreased CCL11 productions in IL-4/IL-1 $\beta$-stimulated HPDLCs. On the other hand, Akt and STAT6 inhibitors enhanced CCL20 productions from HPDLCs stimulated with IL-4 and IL-1 $\beta$ (Fig. 4B).

\section{Discussion}

In this study, we revealed that IL- 4 could increase CCL11 production in IL-1 $\beta$-stimulated HPDLCs. Hirst and the colleagues reported that IL-4 synergistically enhanced CCL11 release from human airway smooth muscle cells stimulated with IL-1 $\beta$ [21]. We previously reported that IL-4 synergistically enhanced CCL11 production in IL-1 $\beta$-stimulated human gingival fibroblasts [6]. Judging from our data and previous reports, the number of Th2 cells in inflammatory lesions might dramatically enhanced when both IL- 4 and IL-1 $\beta$ existed because CCL11 productions positively increased.

We revealed IL-4 could inhibit CCL20 production in HPDLCs in this report. There are few reports about the effect of IL-4 on CCL20 production. Hirota and the colleagues reported that IL-4 decreased CCL20 production from non-stimulated mouse synoviocytes [11]. Their report is similar with ours though we first showed that IL-4 could inhibit CCL20 production in cytokine-stimulated cells. There are some reports that the effect of IL-4 on CCR6, which is a CCL20 receptor, expression. Dieu-Nosjean and the colleagues reported that IL-4 decreased CCR6 expression on cells during differentiation of Langerhans cells [22]. Carramolino and the colleagues reported that IL-4 treatment down-regulated the CCR6 expression on dendritic cells [23]. These reports and our report suggest that IL-4 inhibit CCR6-expressing cells such as Th17 cells, immature dendritic cells, Langerhans cells, migration and accumulation to down-regulate both CCL20 and CCR6.

We revealed STAT6 pathway positively regulated CCL11 production, but negatively controlled CCL20 production from HPDLCs. There are some reports that the role of STAT6 on CCL11 production. Hoeck and the colleague reported that CCL11 production from IL-4stimulated human dermal fibroblasts were dependent on STAT6 activation [24]. Zhou and the colleagues also reported that STAT6 inhibition apparently decreased CCL11 production from IL-13 and TGF- $\beta 1$-stimulated human airway fibroblasts [25]. Previous reports and our report showed that STAT6 activation is essential for CCL11 production in variety of cells. On the other hand, there is no report about the role of STAT6 on CCL20 production. However, CXCL10 and CXCL11, which are Th1-type chemokines, expression were dramatically enhanced in STAT6 knockout mouse than normal mouse [26]. Their report and our report suggest that STAT6 pathway negatively regulated not only Th1-type chemokines, such as CXCL10 and CXCL11 productions, but a Th17-type chemokine, such as CCL20 production.

We showed that Akt pathway negatively regulated CCL20 production in HPDLCs. Rohani and the colleagues reported that PAR1 and PAR2-induced CCL20 were negatively regulated by Akt signaling pathway in oral keratinocytes [27]. Their report agrees with ours. On the other hand, Li and the colleagues reported that CCL20 production from plasmin-stimulated dendritic cells was positively regulated Akt pathway [28]. Judging from our report and previous reports, How Akt modulates CCL20 production is dependent on the types of cells and stimulants.

We report Akt positively regulated CCL11 production in HPDLCs. Smyth and the colleagues reported that LY294002, which is a PI3K inhibitor, decreased CCL11 production from oncostatin M-stimulated mouse fibroblast-like cell line [29]. Rahman and the colleagues also reported that Wortmannin, which is a PI3K inhibitor, down-regulated CCL11 production 
in IL-1 $\beta$-stimuleted human airway smooth muscle cells [30]. Our report and previous reports might show that PI3K/Akt pathway positively regulate CCL11 production.

In this report, we explain that IL-4 might increase the number of Th2 cells, and decrease the number of Th17 cells in periodontal lesion because IL-4 modulate CCL11 and CCL20 productions in HPDLCs. It is known that Th17 cells are related to bone resorption because IL-17 could enhance RANKL expression in periodontal resident cells [31]. On the other hand, Th2 cells could inhibit bone destruction in inflammatory lesion because IL- 4 and IL-13 could induce osteoprotegerin, which is a decoy receptor for the RANKL, in human endothelial cells [32]. Therefore, IL-4 could inhibit alveolar bone destruction in periodontal lesion. Further investigation should be necessary to know the role of IL-4 in periodontal lesion.

In summary, the current study demonstrates that IL- 4 could enhance IL- $1 \beta$-induced CCL11 in HPDLCs though inhibit CCL2 0 production. STAT6 and Akt pathways are important for the CCL11 and CCL20 production in IL-4 treated HPDLCs. Finally, IL-4 is an essential cytokine to control T cells migration and accumulation in periodontal lesions.

\section{Acknowledgements}

This study was supported by Grant-in-Aid for Scientific Research (C) (25463219 and 15K11392) from Japan Society for the Promotion of Science.

\section{Disclosure Statement}

The authors confirm that there are no conflicts of interest.

\section{References}

1 Cekici A, Kantarci A, Hasturk H, Van Dyke TE: Inflammatory and immune pathways in the pathogenesis of periodontal disease. Periodontol 2000 2014;64:57-80.

2 Graves D: Cytokines that promote periodontal tissue destruction. J Periodontol 2008;79:1585-1591.

3 Nakajima M, Honda T, Miyauchi S, Yamazaki K: Th2 cytokines efficiently stimulate periostin production in gingival fibroblasts but periostin does not induce an inflammatory response in gingival epithelial cells. Arch Oral Biol 2014;59:93-101.

4 Hosokawa Y, Hosokawa I, Ozaki K, Nakae H, Matsuo T: Cytokines differentially regulate ICAM-1 and VCAM1 expression on human gingival fibroblasts. Clin Exp Immunol 2006;144:494-502.

5 Hosokawa Y, Hosokawa I, Ozaki K, Nakae H, Matsuo T: CC chemokine ligand 17 in periodontal diseases: expression in diseased tissues and production by human gingival fibroblasts. J Periodontal Res 2008;43:471-477.

6 Hosokawa Y, Hosokawa I, Shindo S, Ozaki K, Matsuo T: (-)-Epigallocatechin-3-gallate inhibits CC chemokine ligand 11 production in human gingival fibroblasts. Cell Physiol Biochem 2013;31:960-967.

7 Jin Z, Shen Y, Fujimoto S: Role of alpha4 integrin and its ligand VCAM-1 in the specific extravasation of a tumor-specific TH2 clone into tumor tissue that initiates its rejection. Int J Cancer 2004;111:558-567.

8 Andrew DP, Chang MS, McNinch J, Wathen ST, Rihanek M, Tseng J, Spellberg JP, Elias CG 3rd: STCP-1 (MDC) CC chemokine acts specifically on chronically activated Th2 lymphocytes and is produced by monocytes on stimulation with Th2 cytokines IL-4 and IL-13. J Immunol 1998;161:5027-5038.

9 Sallusto F, Mackay CR, Lanzavecchia A: Selective expression of the eotaxin receptor CCR3 by human T helper 2 cells. Science 1997;277:2005-2007.

10 Gaffen SL, Hajishengallis G: A new inflammatory cytokine on the block: re-thinking periodontal disease and the Th1/Th2 paradigm in the context of Th17 cells and IL-17. J Dent Res 2008;87:817-828.

11 Hirota K, Yoshitomi H, Hashimoto M, Maeda S, Teradaira S, Sugimoto N, Yamaguchi T, Nomura T, Ito H, Nakamura T, Sakaguchi N, Sakaguchi S: Preferential recruitment of CCR6-expressing Th17 cells to inflamed joints via CCL20 in rheumatoid arthritis and its animal model. J Exp Med 2007;204:2803-2812.

12 Hosokawa Y, Hosokawa I, Ozaki K, Nakae H, Matsuo T: Increase of CCL20 expression by human gingival fibroblasts upon stimulation with cytokines and bacterial endotoxin. Clin Exp Immunol 2005;142:285-291. 


\section{Cellular Physiology Cell Physiol Biochem 2016;38:153-159 \begin{tabular}{l|l|l|l}
\hline DOI: 10.1159/000438617 & $\begin{array}{l}\text { ( ) 2016 The Author(s). Published by S. Karger AG, Basel } \\
\text { www.karger.com/cpb }\end{array}$
\end{tabular} \\ Hosokawa et al.: IL-4 Modulates Chemokine Productions in Fibroblast}

13 Lee JS, Yi JK, An SY, Heo JS: Increased osteogenic differentiation of periodontal ligament stem cells on polydopamine film occurs via activation of integrin and PI3K signaling pathways. Cell Physiol Biochem 2014;34:1824-1834.

14 Qi L, Zhang Y: The microRNA 132 regulates fluid shear stress-induced differentiation in periodontal ligament cells through mTOR signaling pathway. Cell Physiol Biochem 2014;33:433-445.

15 Kimura H, Okubo N, Chosa N, Kyakumoto S, Kamo M, Miura H, Ishisaki A: EGF positively regulates the proliferation and migration, and negatively regulates the myofibroblast differentiation of periodontal ligament-derived endothelial progenitor cells through MEK/ERK- and JNK-dependent signals. Cell Physiol Biochem 2013;32:899-914.

16 Shindo S, Hosokawa Y, Hosokawa I, Ozaki K, Matsuo T: Genipin inhibits IL-1 $\beta$-induced CCL20 and IL-6 production from human periodontal ligament cells. Cell Physiol Biochem 2014;33:357-364.

17 Luo LJ, Liu F, Lin ZK, Xie YF, Xu JL, Tong QC, Shu R: Genistein regulates the IL-1 beta induced activation of MAPKs in human periodontal ligament cells through G protein-coupled receptor 30. Arch Biochem Biophys 2012;522:9-16.

18 Aoudjehane L, Pissaia A Jr, Scatton O, Podevin P, Massault PP, Chouzenoux S, Soubrane O, Calmus Y, Conti F: Interleukin- 4 induces the activation and collagen production of cultured human intrahepatic fibroblasts via the STAT-6 pathway. Lab Invest 2008; 88:973-985.

19 Ceponis PJ, McKay DM, Menaker RJ, Galindo-Mata E, Jones NL: Helicobacter pylori infection interferes with epithelial Stat6-mediated interleukin-4 signal transduction independent of cagA, cagE, or VacA. J Immunol 2003;171:2035-2041.

20 Stein NC, Kreutzmann C, Zimmermann SP, Niebergall U, Hellmeyer L, Goettsch C, Schoppet M, Hofbauer LC: Interleukin-4 and interleukin-13 stimulate the osteoclast inhibitor osteoprotegerin by human endothelial cells through the STAT6 pathway. J Bone Miner Res 2008;23:750-758.

21 Hirst SJ, Hallsworth MP, Peng Q, Lee TH: Selective induction of eotaxin release by interleukin-13 or interleukin-4 in human airway smooth muscle cells is synergistic with interleukin-1beta and is mediated by the interleukin-4 receptor alpha-chain. Am J Respir Crit Care Med 2002;165:1161-1171.

22 Dieu-Nosjean MC, Massacrier C, Vanbervliet B, Fridman WH, Caux C: IL-10 induces CCR6 expression during Langerhans cell development while IL-4 and IFN-gamma suppress it. J Immunol 2001; 167: 5594-5602.

23 Carramolino L, Kremer L, Goya I, Varona R, Buesa JM, Gutiérrez J, Zaballos A, Martínez-A C, Márquez G: Down-regulation of the beta-chemokine receptor CCR6 in dendritic cells mediated by TNF-alpha and IL-4. J Leukoc Biol. 1999;66:837-844.

24 Hoeck J, Woisetschläger M: STAT6 mediates eotaxin-1 expression in IL-4 or TNF-alpha-induced fibroblasts. J Immunol 2001;166:4507-4515.

25 Zhou X, Hu H, Balzar S, Trudeau JB, Wenzel SE: MAPK regulation of IL-4/IL-13 receptors contributes to the synergistic increase in CCL11/eotaxin-1 in response to TGF- $\beta 1$ and IL-13 in human airway fibroblasts. J Immunol 2012;188:6046-6054.

26 Fulkerson PC, Zimmermann N, Hassman LM, Finkelman FD, Rothenberg ME: Pulmonary chemokine expression is coordinately regulated by STAT1, STAT6, and IFN-gamma. J Immunol 2004;173:7565-7574.

27 Rohani MG, DiJulio DH, An JY, Hacker BM, Dale BA, Chung WO: PAR1- and PAR2-induced innate immune markers are negatively regulated by PI3K/Akt signaling pathway in oral keratinocytes. BMC Immunol 2010;11:53.

28 Li X, Syrovets T, Simmet T: The serine protease plasmin triggers expression of the CC-chemokine ligand 20 in dendritic cells via Akt/NF-kB-dependent pathways. J Biomed Biotechnol 2012;2012:186710.

29 Smyth DC, Kerr C, Li Y, Tang D, Richards CD: Oncostatin M induction of eotaxin-1 expression requires the convergence of PI3'K and ERK1/2 MAPK signal transduction pathways. Cell Signal 2008;20:1142-1150.

30 Rahman MS, Yamasaki A, Yang J, Shan L, Halayko AJ, Gounni AS: IL-17A induces eotaxin-1/CC chemokine ligand 11 expression in human airway smooth muscle cells: role of MAPK (Erk1/2, JNK, and p38) pathways. J Immunol 2006;177:4064-4071.

31 Lin D, Li L, Sun Y, Wang W, Wang X, Ye Y, Chen X, Xu Y: IL-17 regulates the expressions of RANKL and OPG in human periodontal ligament cells via TRAF6/TBK1-JNK/NF-kB pathways. Immunology 2015;144:472-485.

32 Stein NC, Kreutzmann C, Zimmermann SP, Niebergall U, Hellmeyer L, Goettsch C, Schoppet M, Hofbauer LC: Interleukin-4 and interleukin-13 stimulate the osteoclast inhibitor osteoprotegerin by human endothelial cells through the STAT6 pathway. J Bone Miner Res 2008;23:750-758. 